\title{
Studies on Hydrogenation of Liquid Natural Rubber Using Diimide
}

\author{
Nur Hanis Adila Azhar, Naharullah Jamaluddin, Hamizah Md Rasid, \\ Muhammad Jefri Mohd Yusof, and Siti Fairus M. Yusoff
}

School of Chemical Sciences and Food Technology, Faculty of Science and Technology, Universiti Kebangsaan Malaysia, 43600 Bangi, Selangor, Malaysia

Correspondence should be addressed to Siti Fairus M. Yusoff; sitifairus@ukm.edu.my

Received 14 May 2015; Revised 2 July 2015; Accepted 6 July 2015

Academic Editor: Chuanbing Tang

Copyright ( 2015 Nur Hanis Adila Azhar et al. This is an open access article distributed under the Creative Commons Attribution License, which permits unrestricted use, distribution, and reproduction in any medium, provided the original work is properly cited.

\begin{abstract}
Liquid natural rubber (LNR) is a depolymerized natural rubber (NR) which consists of shorter polymeric chains and lower molecular weight $\left(M_{w}<10^{5}\right)$. Hydrogenated LNR (HLNR) was synthesized via the thermal decomposition of $p$-toluenesulfonyl hydrazide (TSH) or 2,4,6-trimethylbenzenesulfonyl hydrazide (MSH). The LNR and HLNR structures were characterized by Fourier-transform infrared (FTIR) and nuclear magnetic resonance (NMR) spectroscopies. The percentage of hydrogenation was calculated from NMR spectrum. The optimum percentage of hydrogenation $(>90 \%)$ was achieved by manipulating the reaction parameters such as sources of diimide, TSH concentration, solvent, and reaction time. The optimum condition was $3: 1$ weight ratio of TSH/LNR in $o$-xylene at $130^{\circ} \mathrm{C}$ in 4 -hour reaction period.
\end{abstract}

\section{Introduction}

Natural rubber (NR) is one of the most valuable renewable resources extracted from the rubber tree, Hevea brasiliensis. The main components in NR are rubber particles (30$40 \%)$, water (55-65\%), protein (2-3\%), sterol glycosides (0.1$0.5 \%)$, resin (1.5-3.5\%), ash (0.5-1.0\%), and carbohydrate $(1.0-2.0 \%)[1,2]$. NR is well known for its outstanding elastic property and high mechanical strength. It has attracted great interest in various fields and is used extensively in many applications and products. However, NR has poor heat resistance and low resistance to weather and chemical reagents due to its unsaturated $\mathrm{C}=\mathrm{C}$ bonds, thus limiting its use in outdoor application. To increase the level of saturation, hydrogenation, a simple chemical modification, can enhance the stability against thermal and oxidative degradation of NR.

Liquid natural rubber (LNR) is defined as a modified natural rubber having similar microstructure as NR but with shorter polymeric chains and lower molecular weights $\left(M_{w}<\right.$ $10^{5}$ ). The presence of a reactive and unsaturated bond in
LNR offers many possibilities for chemical modifications. In contrast to dried rubber, the use of LNR is advantageous for the production of various products because it can be processed easily and requires less energy [3]. LNR has two major advantages over the synthetic rubbers. Firstly, the synthetic route for the preparation of LNR is more green/renewable and more energy efficient than other technologies such as metathesis degradation and cleavage by periodic acid/lead tetra acetate [4-6]. Secondly, NR can be obtained from natural resources (green route).

Hydrogenation is one of the most efficient methods to transform the unsaturated part of natural rubber (NR) into saturated moiety and alter and improve physical properties of unsaturated polymers. The hydrogenation of NR can be carried out by two main methods such as catalytic (homogeneous and heterogeneous) and noncatalytic hydrogenation. Catalytic hydrogenation is the reaction of catalyst that will activate hydrogen molecules and the carbon-carbon double bond species [7]. In the presence of catalysts, hydrogenation of polymers is difficult and generally unsatisfactory. This 


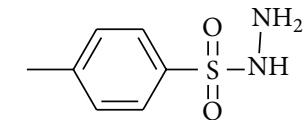

p-Toluenesulfonyl hydrazide

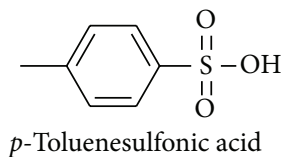

p-Toluenesulfonic acid

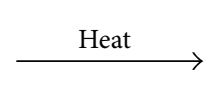

$+$<smiles>[Y10]CC(C)CCCCC</smiles>

$\mathrm{N}_{2} \mathrm{H}_{2}$

Diimide
$2 \mathrm{NH}=\mathrm{NH} \quad \longrightarrow \quad \mathrm{N}_{2} \quad+\quad \mathrm{N}_{2} \mathrm{H}_{4}$

SCHEME 1: Hydrogenation of LNR using TSH.

is due to the high tendency of polymer molecules to be absorbed on catalysts, thus rendering the catalysts inefficient or ineffective. Double bonds in the polymers can be reduced successfully when high temperatures, large amounts of catalyst, and high hydrogen pressures are employed, but chain cleavage is also promoted by severe hydrogenation conditions and low molecular weight products [8-10].

A noncatalytic hydrogenation is a method using diimide molecule that releases hydrogen molecules to the carboncarbon double bond of the unsaturated polymers. The reaction is carried out under milder conditions compared to catalytic hydrogenation, such as low pressure and requiring simple apparatus $[11,12]$. The diimide molecule can be generated by methods such as the oxidation of hydrazine, the thermal decomposition of arenesulfonylhydrazides, and the photochemical irradiation of 1-thia-3,4-diazolidine-2,5dione [13]. $p$-Toluenesulfonyl hydrazide (TSH) and 2,4,6trimethylbenzenesulfonyl hydrazide (MSH) have been used to hydrogenate the carbon-carbon double bond of unsaturated polymer [14].

The objectives of this work were to study the noncatalytic hydrogenation of liquid natural rubber via the thermolysis of TSH and MSH. The diimide generated from thermal decomposition of TSH releases hydrogen molecule to the $\mathrm{C}=\mathrm{C}$ of the LNR (Scheme 1) $[15,16]$. We also studied the effect of diimide source, TSH concentration, solvent, and reaction time against the percentage of hydrogenation. The reaction scheme of this reaction was shown in Scheme 1.

\section{Materials and Methods}

2.1. Materials. In this work, we used natural rubber from Rubber Research Institute of Malaysia (RRIM). Toluene (>99\%), o-xylene (>99\%), ethanol (95\%), and methanol (>99.8\%) were supplied by R\&M Chemicals (Himachal Pradesh, India). Methylene blue ( $\geq 95 \%)$, rose Bengal (95\%), p-toluenesulfonyl hydrazide (TSH) (97\%), and 2,4,6-trimethylbenzenesulfonyl hydrazide (MSH) (97\%) were purchased from Sigma Aldrich (Missouri, USA).
2.2. Hydrogenation of LNR. LNR with $10 \%$ of dry rubber content was prepared [17]. TSH was used as a diimide source in the hydrogenation reaction. Different amounts of TSH were added to a fixed volume of LNR solution at TSH/LNR weight ratios of $1: 1$ to $3: 1$ to determine the effect of TSH concentration on the percentage of hydrogenation. Each mixture was heated to a temperature $130^{\circ} \mathrm{C}$ and stirred for 15 hours to study the effect of reaction time on the percentage of hydrogenation. The products were filtered and coagulated with ethanol to remove the residual TSH. Finally, it was dried in a vacuum oven to remove any remaining solvent. In this work, we also studied the effect of diimide source by using MSH. $o$-Xylene and toluene were used to identify the effect of solvent on the percentage of hydrogenation LNR.

2.3. Characterization. Fourier-transform infrared (FTIR) and nuclear magnetic resonance (NMR) spectroscopies were used to determine the structure of the products formed. Attenuated total reflectance-Fourier-transform infrared (ATR-FTIR) spectroscopy (Perkin Elmer) was used to determine any change in the functional groups that might have been induced by the hydrogenation reaction. The samples were analyzed in transmittance mode within the range $4000-600 \mathrm{~cm}^{-1}$. NMR spectroscopy was used to examine the microstructure of the product. Integration of signals from proton NMR ( ${ }^{1} \mathrm{H}$ NMR) was used to estimate the percentage of conversion from LNR to HLNR. Samples were dissolved in $\mathrm{CDCl}_{3}$ for measurements with the Fourier-Transform Nuclear Magnetic Resonance $600 \mathrm{MHz}$ Cryoprobe (FT-NMR $600 \mathrm{MHz}$ Cryo). The degradation temperatures of samples were determined by using thermogravimetric analysis (TGA) and differential thermal analysis (DTA) (TGA/SDTA $851^{\mathrm{e}}$, Mettler Toledo, Switzerland). Gel permeation chromatography (GPC) was used to investigate the molecular weight $\left(M_{w}\right)$ and polydispersity index (PDI) of LNR and HLNR (Waters 1515 Isocratic HPLC Pump equipped with a Waters 2414 Refractive Index detector, Waters Corporation, USA). 


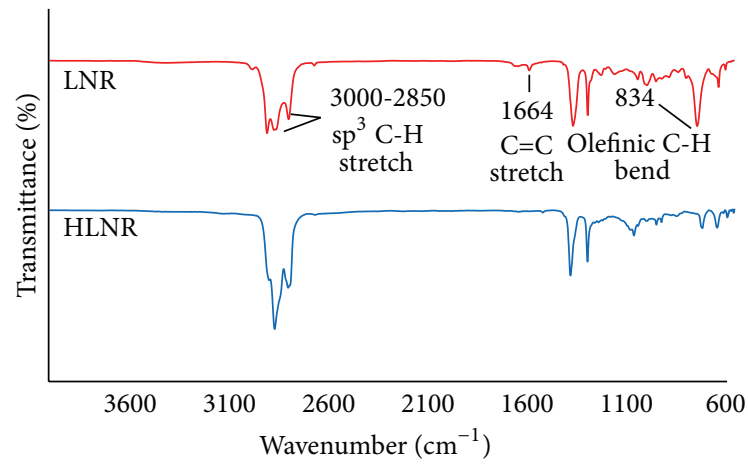

FIGURE 1: FTIR spectra of LNR and HLNR (95.9\%).

\section{Results and Discussion}

3.1. Structure of LNR and HLNR. The microstructures of LNR and HLNR at $95.9 \%$ hydrogenation were characterized by FTIR, and the spectra are shown in Figure 1. The main peaks are located at 3000-2850, 1664, and $834 \mathrm{~cm}^{-1}$ corresponding to $\mathrm{sp}^{3} \mathrm{C}-\mathrm{H}$ stretching, $\mathrm{C}=\mathrm{C}$ stretching, and olefinic $\mathrm{C}-\mathrm{H}$ bending, respectively. The intensity of $\mathrm{sp}^{3} \mathrm{C}-\mathrm{H}$ stretching is increased as a result of hydrogenation of LNR whereby the intensity of the other two peaks is decreased due to the reduced amount of $\mathrm{C}=\mathrm{C}$ and olefinic $\mathrm{C}-\mathrm{H}$. Several peaks between 1500 and $900 \mathrm{~cm}^{-1}$ are more intense than they appear in the LNR spectrum, and the stronger signals in that range originated from the paraffin $\mathrm{C}-\mathrm{H}$ bending vibrations owing to the increasing number of alkane groups after hydrogenation.

The ${ }^{1} \mathrm{H}$ NMR spectra of LNR and HLNR are shown in Figure 2. The spectrum of LNR shows signals at 1.73, 2.02 , and $5.12 \mathrm{ppm}$, which are assigned to the protons of unsaturated methyl $\left(\mathrm{R}-\mathrm{CH}_{3}\right)$, unsaturated methylene (R$\left.\mathrm{CH}_{2}-\mathrm{R}\right)$, and olefinic $\left(\mathrm{R}-\mathrm{CH}=\mathrm{C}-\mathrm{R}_{2}\right)$, respectively. After hydrogenation, these signals are reduced and new signals appear in the range of $0.85-1.39 \mathrm{ppm}$, corresponding to the methane $\left(\mathrm{CH}_{4}\right)$, methylene $\left(-\mathrm{CH}_{2}-\right)$, and methyl $\left(-\mathrm{CH}_{3}\right)$ groups. The percentage of hydrogenation was calculated from the ratio between the integration of the olefinic proton signal and integration of the signals in the range of $0.8-2.2 \mathrm{ppm}$. The signals around 2.3-2.5 ppm correspond to benzylic proton from $o$-xylene, toluene, and TSH. Meanwhile, the signal at $3.7 \mathrm{ppm}$ corresponds to the ethanol used for coagulation. In conclusion, the FTIR and NMR spectra show the microstructural changes that occurred during hydrogenation.

3.2. Thermal Analysis of LNR and HLNR. Thermogravimetric analysis (TGA) and differential thermal analysis (DTA) were carried out to determine the degradation temperature of LNR and HLNR. According to Figure 3, below $316^{\circ} \mathrm{C}$, LNR thermogram slightly decreased at the early stage because of the evaporation of toluene in LNR. HLNR is quite stable below $398^{\circ} \mathrm{C}$. Thermograms of TGA and DTA showed that the degradation of LNR occurred in two stages, while HLNR occurred in one stage. The first stage degradation of LNR
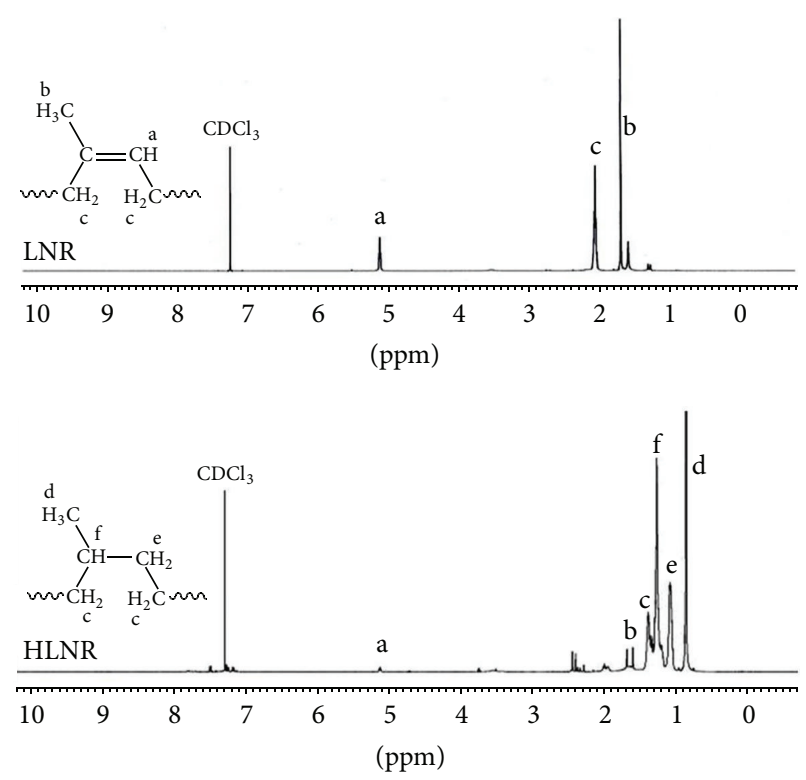

FIgURE 2: ${ }^{1} \mathrm{H}$ NMR spectra of LNR and HLNR (95.9\%).

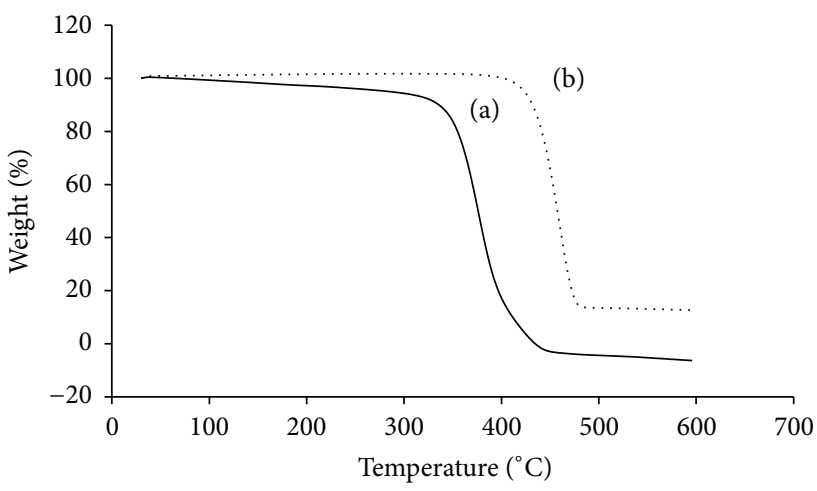

FIgURE 3: TGA thermograms of (a) LNR and (b) HLNR at $95.9 \%$ of hydrogenation.

started at $316^{\circ} \mathrm{C}$ and ended at $403^{\circ} \mathrm{C}$. In this stage, a weight loss of $78.37 \%$ was observed. The second stage degradation of LNR started at temperature above $403^{\circ} \mathrm{C}$ until $444^{\circ} \mathrm{C}$. During this stage, the weight loss was $17.16 \%$. Beyond $444^{\circ} \mathrm{C}$, the weight loss during this stage was $4.04 \%$ that corresponded to the cyclized rubber [18].

Meanwhile, the degradation of $95.9 \%$ HLNR started at $398^{\circ} \mathrm{C}$ and ended at $473^{\circ} \mathrm{C}$. From the thermograms of DTA (Figure 4), the degradation temperatures of $\operatorname{LNR}\left(374^{\circ} \mathrm{C}\right)$ and HLNR at $95.9 \%\left(462^{\circ} \mathrm{C}\right)$ can be seen more clearly by the maximum peaks in the thermograms. Based from the result obtained, hydrogenation reaction had been proven to increase the thermal stability of LNR with increasing percentage of hydrogenation having higher degradation temperature.

3.3. Molecular Weight of LNR and HLNR. Gel permeation chromatography (GPC) is a separation method based on relative size for polymers. GPC is used to determine the 


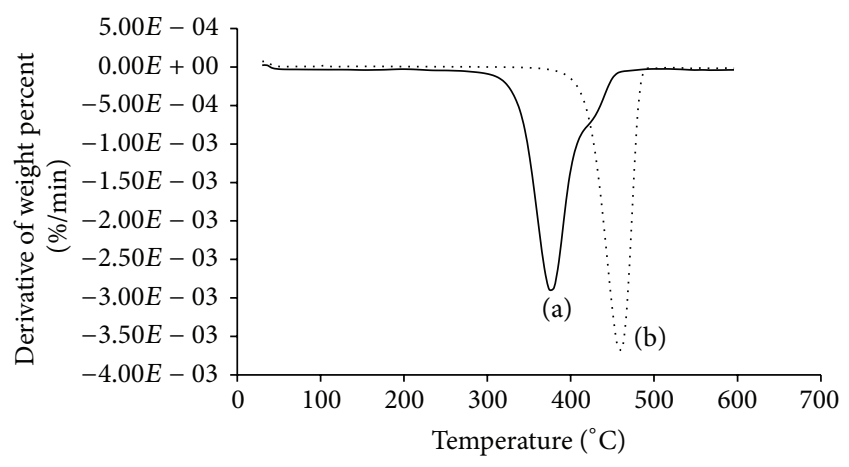

FIgURE 4: DTA thermograms of (a) LNR and (b) HLNR at $95.9 \%$ hydrogenation.

molecular weight and PDI of LNR and HLNR. The number average molecular weight $\left(M_{n}\right)$, weight average molecular weight $\left(M_{w}\right)$, and polydispersity index (PDI) of LNR and HLNRs are listed in Table 1 . The $M_{w}$ of natural rubber is more than $10^{7}[19]$. The $M_{w}$ and PDI of LNR were $88400 \mathrm{u}$ and 8.11, respectively. After hydrogenation, the $M_{w}$ and PDI of HLNRs reduced due to the high reaction temperature $\left(130^{\circ} \mathrm{C}\right)$ and long reaction time (4 hours) [16]. However, the percentage of hydrogenation did not give significant difference in $M_{w}$ and PDI, since the reactions were done in the same reaction temperature and time.

3.4. Effect of Diimide Source. Several experiments were conducted by using different sources of diimide (TSH and MSH). According to Cusack et al., the thermal decomposition of $\mathrm{MSH}$ is 24 times that of TSH. MSH is a better diimide source for the hydrogenation of LNR compared to TSH due to its decomposition rate. Besides that, $\mathrm{MSH}$ also produces a more stable system [20]. In this work, we used TSH and MSH to study the effect of diimide sources on the percentage of hydrogenation. Table 2 shows the data of this study. By the weight ratio of $1: 1$ between LNR and sources of diimide, MSH gives a higher percentage of hydrogenation, $68.4 \%$, in a shorter reaction time which is only 50 minutes. Otherwise, TSH only gives $41.4 \%$ of hydrogenation even after 4 hours of reaction time. It indicated that MSH can perform faster hydrogenation reaction compared to TSH due to its higher rate of decomposition. The other factor that can attribute to the result is the amount of reactants used to conduct the experiment.

3.5. Effect of TSH Concentration. The weight ratio of TSH to LNR was varied from 1:1 until 3:1 in order to study the influence of TSH concentration on percent of hydrogenation, while the other parameters are kept constant. Table 3 shows that increasing weight ratio of TSH to LNR will gradually increase the percentage of hydrogenation. From the analysis of NMR spectroscopy, the optimum weight ratio was achieved at $3: 1$ since the hydrogenation level exceeded $90 \%$. Higher amount of TSH provides more source of hydrogen, hence increasing its hydrogenation percentage. In conclusion,
TABLE 1: Molecular weight and PDI of LNR and HLNR.

\begin{tabular}{lccc}
\hline Sample & $M_{n}$ & $M_{w}$ & PDI \\
\hline LNR & 10900 & 88400 & 8.11 \\
HLNR (41.4\%) & 28400 & 67000 & 2.36 \\
HLNR (72.5\%) & 26900 & 55600 & 2.07 \\
HLNR (95.9\%) & 25900 & 58800 & 2.27 \\
\hline
\end{tabular}

TABLE 2: Effect of diimide source on the hydrogenation of LNR.

\begin{tabular}{lccc}
\hline Experiment Source of diimide & $\begin{array}{c}\text { Percentage of } \\
\text { hydrogenation } \\
(\%)\end{array}$ & Reaction time \\
\hline 1 & $\mathrm{TSH}$ & 41.4 & 4 hours \\
2 & $\mathrm{MSH}$ & 68.4 & 50 minutes \\
\hline $\begin{array}{l}\text { Condition: weight ratio of }(\mathrm{TSH} / \mathrm{MSH}) / \mathrm{LNR}=1: 1, T=130^{\circ} \mathrm{C} \text {, and solvent }= \\
o \text {-xylene. }\end{array}$
\end{tabular}

TABLE 3: Effect of TSH concentration on the hydrogenation of LNR.

\begin{tabular}{lcc}
\hline Experiment & $\begin{array}{c}\text { Weight ratio of } \\
\text { TSH/LNR }\end{array}$ & $\begin{array}{c}\text { Percentage of } \\
\text { hydrogenation } \\
(\%)\end{array}$ \\
\hline 3 & $1: 1$ & 41.4 \\
4 & $2: 1$ & 72.5 \\
5 & $3: 1$ & 95.9 \\
\hline Condition: source of diimide $=\mathrm{TSH}, T=130^{\circ} \mathrm{C}$, solvent $=o$-xylene, and \\
time =4 hours.
\end{tabular}

TABLE 4: Effect of solvent on the hydrogenation of LNR.

\begin{tabular}{lcc}
\hline Experiment & Solvent & Percentage of hydrogenation (\%) \\
\hline 6 & Toluene & 72.6 \\
7 & $o$-Xylene & 95.9 \\
\hline
\end{tabular}

Condition: source of diimide $=\mathrm{TSH}$, weight ratio of TSH/LNR $=3: 1, T=$ $130^{\circ} \mathrm{C}$, and time $=4$ hours.

the percentage of hydrogenation is directly proportional to weight ratio of TSH/LNR.

3.6. Effect of Solvent. A few of reactions were carried out to study the effect of solvent used on the degree of hydrogenation of LNR. Whilst the other parameters are being fixed, the solvent used is swapped from toluene to $o$-xylene to investigate the effect of solvent used. Based on TSH/LNR ratio of $3: 1$ at $130^{\circ} \mathrm{C}$ in 4 -hour reaction period, $o$-xylene is more effective as a solvent (95.9\% hydrogenation) compared to toluene $(72.6 \%$ hydrogenation) with the same reaction parameters. By using toluene, hydrogenation above $90 \%$ only can be achieved after 6-hour reaction time. Table 4 illustrates the comparison of the hydrogenation percentage between toluene and $o$-xylene. TSH is likely to dissolve in $o$-xylene to a greater extent than toluene and easily produces diimide that reacts with carbon-carbon double bonds to achieve a higher percentage of hydrogenation [16]. For the conclusion, $o$-xylene is a better solvent to use compared to toluene for 


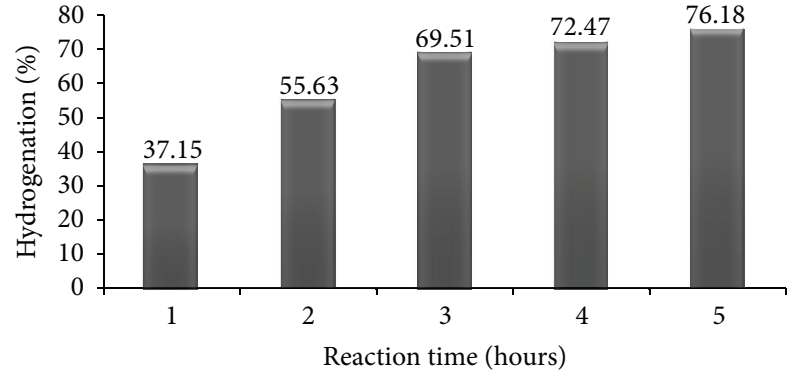

FIGURE 5: Effect of reaction time on the hydrogenation of LNR. Condition: source of diimide $=\mathrm{TSH}$, weight ratio of TSH/LNR = $2: 1, T=130^{\circ} \mathrm{C}$, and solvent $=o$-xylene .

getting hydrogenation above $90 \%$ in this study because the reaction time needed is shorter.

3.7. Effect of Reaction Time. The effect of reaction time on LNR hydrogenation was investigated by varying the reaction time from 1 to 5 hours. Weight ratio TSH/LNR, temperature, and solvent used were kept constant at $2: 1,130^{\circ} \mathrm{C}$ and $o$ xylene, respectively. From 1 to 3 hours of reaction time, the increments are significantly increased, but on the 4 th and 5 th hours, there are only small increments recorded (Figure 5). In 1 to 3 hours, degree of hydrogenation is increased rapidly as the time increased. At 4 hours of reaction time, the hydrogenation increases slightly since the diimide source is insufficient to obtain the optimum hydrogenation followed by the 5th hour. On the bright side, the increase trend of degree of hydrogenation still can be seen, which concludes that the percentage of hydrogenation is directly proportional to the reaction time.

\section{Conclusions}

In summary, a TSH/LNR weight ratio of $3: 1$ yielded a hydrogenation percentage of $95.9 \%$ after 4 hours of reaction at $130^{\circ} \mathrm{C}$ with $o$-xylene as solvent. LNR's thermal stability had been proven to increase from $374^{\circ} \mathrm{C}$ to $462^{\circ} \mathrm{C}$ after $95.9 \%$ conversion of hydrogenation.

\section{Conflict of Interests}

The authors declare that there is no conflict of interests regarding the publication of this paper.

\section{Acknowledgments}

The authors would like to acknowledge Universiti Kebangsaan Malaysia (UKM) for the research grants (FRGS/1/2013/ ST01/UKM/02/03, DIP-2014-16 and 03-01-02-SF1207) and Centre for Research and Instrumentation (CRIM) at UKM for their facilities.

\section{References}

[1] K. W. Poh, "Developments of natural rubber latex. Production, properties, stability," Elastomerics, vol. 12, no. 12, pp. 12-15, 1989.

[2] V. J. Tomazic-Jezic, D. H. Beezhold, H. Hashim et al., "Performance of methods for the measurement of natural rubber latex (NRL) proteins, antigens and allergens," Journal of Allergy and Clinical Immunology, vol. 113, no. 2, p. 78, 2004.

[3] Y. Tanaka, T. Sakaki, A. Kawasaki, M. Hayashi, E. Kanamaru, and K. Shibata, "Production process of depolymerized natural rubber," United States Patent no. 5856600, 1999.

[4] D. R. Burfield and S. N. Gan, "Determination of epoxy groups in natural rubber by degradation methods," Polymer, vol. 18, no. 6, pp. 607-611, 1977.

[5] S. Gillier-Ritoit, D. Reyx, I. Campistron, A. Laguerre, and R. P. Singh, "Telechelic cis-1,4-oligoisoprenes through the selective oxidolysis of epoxidized monomer units and polyisoprenic monomer units in cis-1,4-polyisoprenes," Journal of Applied Polymer Science, vol. 87, no. 1, pp. 42-46, 2003.

[6] P. N. Thanki, D. Reyx, I. Campistron, A. Laguerre, and R. P. Singh, "Metathetic alkenolysis of unsaturated units in polymers and copolymers-application to the synthesis of epoxyfunctionalized oligomers and organic compounds," European Polymer Journal, vol. 40, no. 11, pp. 2611-2616, 2004.

[7] A. Alshaibani, Z. Yaakob, and A. Ghaleb, "Optimization of sunflower oil hydrogenation on $\mathrm{Pd}-\mathrm{B} / \gamma-\mathrm{Al}_{2} \mathrm{O}_{3}$ catalyst," Oriental Journal of Chemistry, vol. 30, no. 1, pp. 167-180, 2014.

[8] R. V. Jones, C. W. Moberly, and W. B. Reynolds, "Hydrogenated synthetic elastomers," Industrial and Engineering Chemistry, vol. 45, no. 5, pp. 1117-1122, 1953.

[9] A. I. Yakubchik and G. N. Gromova, "Hydrogenation of butadiene rubber," Rubber Chemistry and Technology, vol. 31, no. 1, pp. 156-165, 1958.

[10] A. I. Yakubchik, V. N. Reikh, B. I. Tikhomirov, and A. V. Pavlikova, "Effect of hydrogenation on the properties of polybutadiene rubbers," Rubber Chemistry and Technology, vol. 35, no. 4, pp. 1052-1059, 1962.

[11] H. J. Harwood, D. B. Russell, J. J. A. Verthe, and J. Zymonas, "Diimide as a reagent for the hydrogenation of unsaturated polymers," Die Makromolekulare Chemie, vol.163, no. 1, pp. 1-12, 1973.

[12] L. A. Mango and R. W. Lenz, "Hydrogenation of unsaturated polymers with diimide," Die Makromolekulare Chemie, vol. 163, no. 1, pp. 13-36, 1973.

[13] M. Squillacote, J. De Felippis, and L. L. Yu, "Hydrogenation via photochemically generated diimide," Tetrahedron Letters, vol. 34, no. 26, pp. 4137-4140, 1993.

[14] S. Kohjiya and Y. Ikeda, "Chemical modification of natural rubber (NR) for improved performance," in Chemistry, Manufacture and Applications of Natural Rubber, P. Phinyocheep, Ed., chapter 3, pp. 68-86, Elsevier, Cambridge, UK, 2014.

[15] S. Hünig, H. R. Müller, and W. Thier, "The chemistry of diimine," Angewandte Chemie International Edition in English, vol. 4, no. 4, pp. 271-280, 1965.

[16] A. Mahittikul, P. Prasassarakich, and G. L. Rempel, "Noncatalytic hydrogenation of natural rubber latex," Journal of Applied Polymer Science, vol. 103, no. 5, pp. 2885-2895, 2007.

[17] I. Abdullah, "Process for manufacturing liquid natural rubber (LNR)," Malaysian Patent MY-108852-A, 1996. 
[18] R. Asaletha, M. G. Kumaran, and S. Thomas, "Thermal behaviour of natural rubber/polystyrene blends: thermogravimetric and differential scanning calorimetric analysis," Polymer Degradation and Stability, vol. 61, no. 3, pp. 431-439, 1998.

[19] A. Subramaniam, "Gel permeation chromatography of natural rubber," Rubber Chemistry and Technology, vol. 45, no. 1, pp. 346-358, 1972.

[20] N. J. Cusack, C. B. Reese, A. C. Risius, and B. Roozepeikar, "2,4,6-tri-isopropylbenzenesulphonyl hydrazide: a convenient source of di-imide," Tetrahedron, vol. 32, no. 17, pp. 2157-2162, 1976. 

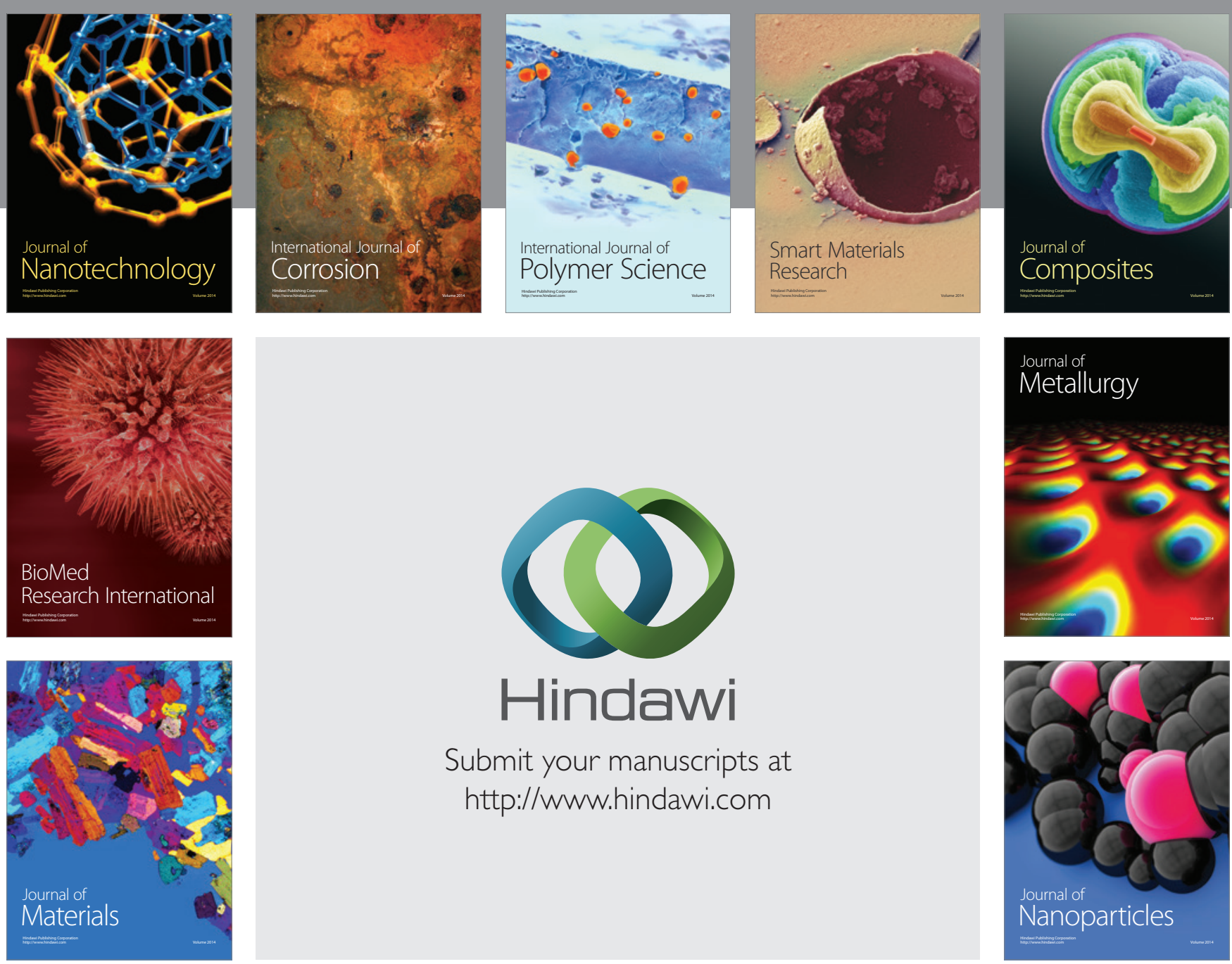

Submit your manuscripts at http://www.hindawi.com
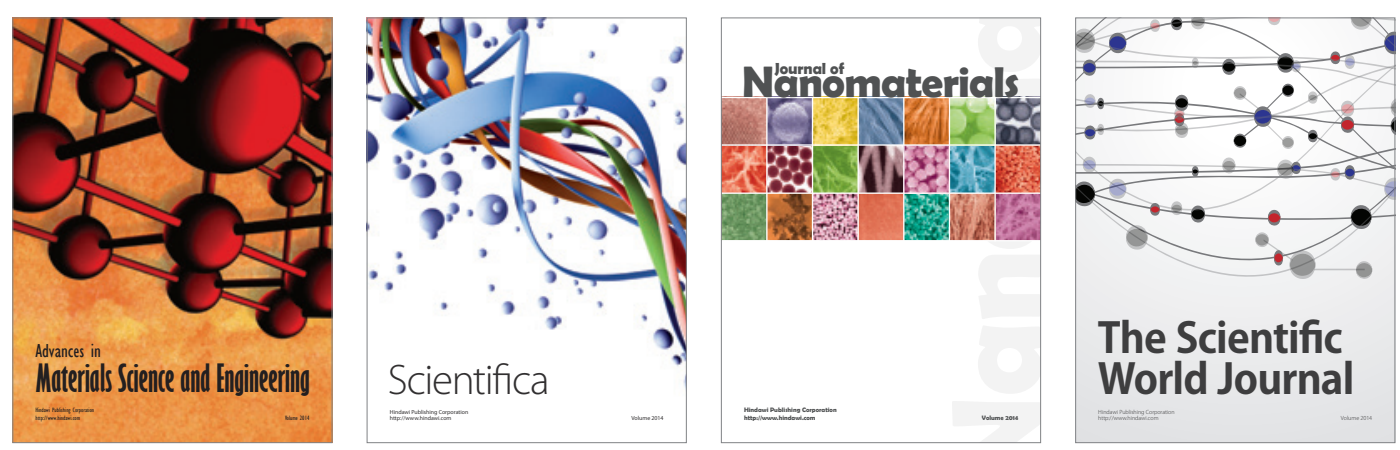

\section{The Scientific World Journal}
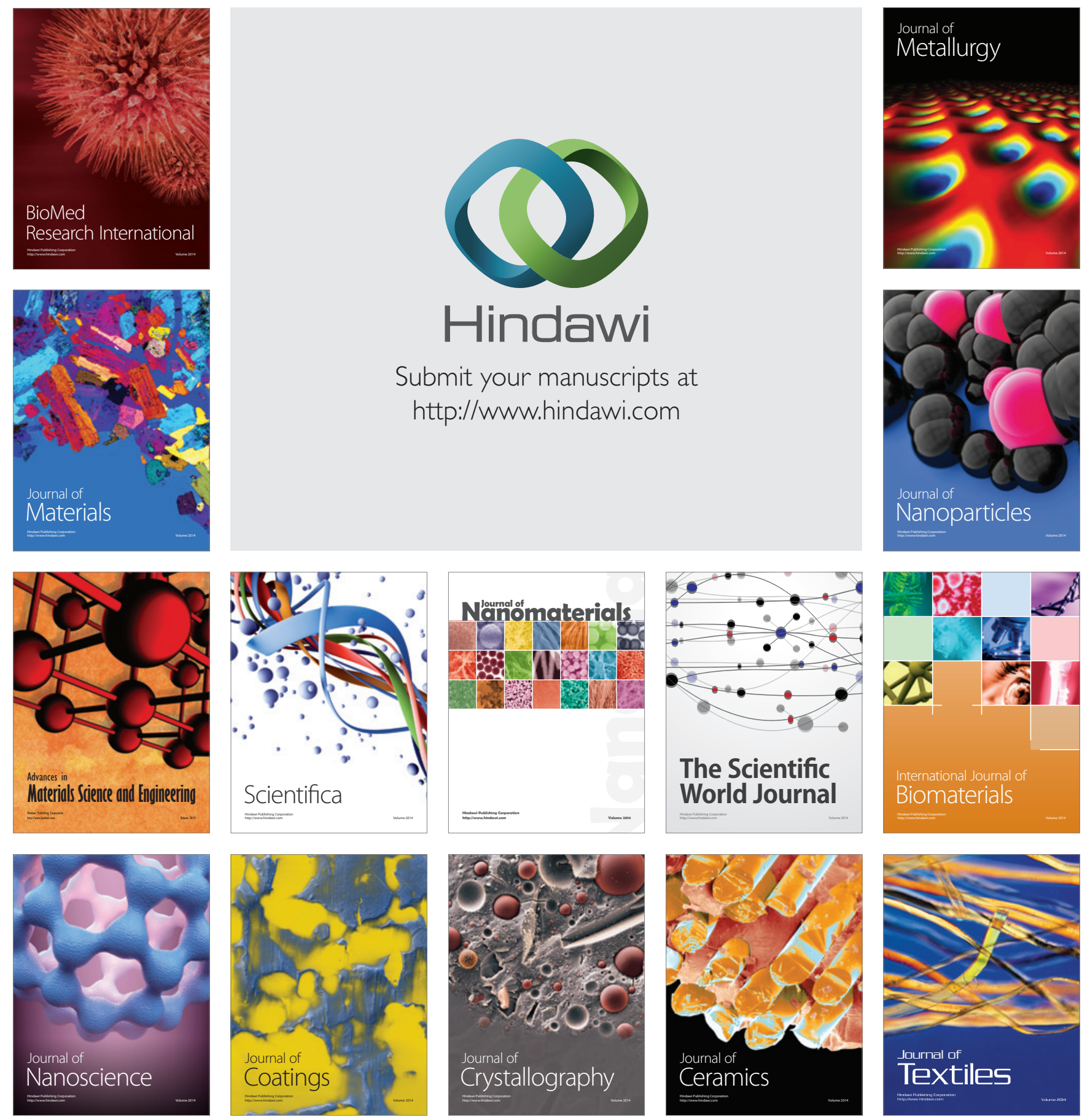